\title{
c-DNA of HIV-I detection on spot of Buffy-Coat of leukocytes (DBCS)
}

\author{
Marco Rossi de Gasperis', Maria Daniela Caione', Carlo Concato', Ersilia Fiscarelli², Nicola Di Pietro, \\ Vittorio Salotti ${ }^{3}$, Lorenza Putignani', Donato Menichella', Francesco Callea ${ }^{2}$ \\ I Dipartimento dei Laboratori- Ospedale Pediatrico Bambino Gesù I.R.C.C.S., Roma, ITALIA; \\ 2 GeneDia Lammari (Lucca), ITALIA;
}

Key words: HIV-I (Human Immunodeficiency Virus Type I), DBS (Dried Blood Spot), DBCS (Dried Buffy Coat Spot)

Ricerca del c-DNA di HIV-I su spot di Buffy-Coat leucocitario (DBCS)

\section{SUMMARY}

Introduction: The elective way for the diagnosis of HIV-I-infection in the window period and in children under the age of $16-18$ months is to search virus integrated in leukocytes.

Aim of the study was to assess the sensitivity and specificity of extraction from Buffy-Dried Coat Spot (DBCS) in leukocyte to detect c-DNA with nested-PCR in HIV-I-infected individuals compared to Dried Blood Spot (DBS) both extracted by automated instrument EZI (QIAGEN, Hilden, Germany). Both DBCS and both DBS were compared with those tests from whole blood by conventional DNA-extraction Methods: Five $\mathrm{ml}$ of whole blood from $50 \mathrm{HIV}$-infected individuals were collected. $40 \mu \mathrm{l}$ of each sample were spotted on "FTA ELUTE Micro Card" (Whatman, Inc., Clifton, NJ), $200 \mu \mathrm{l}$ were extracted according to the manual procedure (QIAGEN "QIAamp DNA minikit) and the remaining sample was incubated at $37^{\circ} \mathrm{C}$ for 120 minutes. Plasma was centrifuged at $1000 \mathrm{rcf} / \mathrm{lg}$ for 10 minutes at room temperature. Forty $\mu \mathrm{l}$ of the obtained buffy-coat was spotted. Both DBCS and both DBS were dried at room temperature for 24 hours. Two of 5 punch from each spot were extracted with TISSUE DNA kit (Biorobot EZI DSP "Qiagen") and eluted in $50 \mu$ l of buffer. The recovery of genomic DNA was measured amplifying the B-globin gene by Real-Time "SybrGreen I". The DNA was amplified for the "pol" gene of HIV-I by nested PCR and revealed in "SYBR-green I". Eight HIV-antibody-negative samples were used as internal control.

Results: The experimental protocol adopted for the DBCS showed high sensitivity and specificity. The extracted DNA from DBS and DBCS was characterized by excellent quality and without any inhibitory agents. The amount of proviral DNA extracted from DBCS is similar to that obtained by conventional extraction, while the DBS test was significantly less sensitive.

Conclusion:These preliminary data suggest that the amount of c-DNA obtained with DBS technique is often not enough for the diagnosis of HIV-I. Recovery of HIV-I proviral c-DNA obtained by DBCS assay seems to provide higher sensitivity compared to the DBS-based extraction procedure.Furthermore seems to be equivalent to the whole blood manual extraction yield.Additionally, the SybrGreen I detection system shows a similar sensitivity and specificity compared to the traditional agarose gel detection and appears to be less expensive.

\section{INTRODUZIONE}

Il metodo di elezione per diagnosticare l’infezione da HIV-1 nel periodo finestra e nei bambini di età inferiore a 16-18 mesi è la ricerca del virus integrato nei leucociti (c-DNA). Nel 2007 trenta paesi a basso e medio reddito hanno adottato un nuovo metodo per la raccolta del sangue necessario al test diagnostico per l'HIV: il Dried Blood Spot Testing. Il Dried Spot è un interessante e semplice metodo che utilizza una speciale carta da filtro per la campionatura, il trasporto sicuro, la conservazione di campioni biologici e l'esecuzione di test diagnostici in laboratori di riferimento posti in località anche molto distanti dai luoghi di prelevamento.

\section{SCOPO}

L'obiettivo del nostro studio è stato quello di valutare sensibilità e specificità di estrazione da Dried Buffy-Coat Spot (DBCS) leucocitario per la ricerca e la diagnosi in nested- PCR di c-DNA di HIV-1, ed un suo confronto con il Dried Blood Spot (DBS), entrambi estratti per mezzo della strumentazione automatica EZ1 (Biorobot EZ1 DSP, Qiagen). I risultati ottenuti dagli estratti da DBCS e DBS sono confrontati con quelli relativi agli stessi campioni estratti da sangue intero, sui quali è stata eseguita una procedura di estrazione convenzionale.

\section{RAZIONALE}

Uno spot di Micro Card (FTA ELUTE Micro Card,Whatman, Inc., Clifton, NJ) di $11 \mathrm{~mm}$ di diametro contiene al massimo $40 \mu \mathrm{l}$ di sangue intero. La metodica relativa all'estrazione da DBS (Dried Blood Spot) applicata alla strumentazione automatica Biorobot EZ1 consiglia di prelevare da uno spot quattro punches da $3.5 \mathrm{~mm}$ di diametro per un totale di $27.22 \mu \mathrm{l}$ di sangue intero. L'estrazione tradizionale manuale per la ricerca del DNA dell'HIV intergrato (QIAMP DNA Blood) utiliz- za $200 \mu \mathrm{l}$ di sangue intero che contengono 4-8 $\mu$ g di DNA in un eluito di $100 \mu \mathrm{l}$ di buffer. L'estrazione di tutto uno spot di $40 \mu \mathrm{l}$ di sangue, avente una concentrazione di DNA di circa 0.8-1.6 $\mu$ g nello stesso volume finale, porta inevitabilmente ad una riduzione di sensibilità dell'indagine confrontata con un'estrazione manuale tradizionale; se a questo aggiungiamo che la metodica prevede di utilizzare quattro punches da 3.5 $\mathrm{mm}(0.54-1.1 \mu \mathrm{g}$ di DNA) o due punches da $5 \mathrm{~mm}(0.55 / 1.11$ $\mu \mathrm{g}$ di DNA), come nel nostro esperimento, nello stesso volume di eluizione $(100 \mu \mathrm{l})$ abbiamo per la grande differenza di quantità di DNA, rispetto al campione di $200 \mu$ l, una ulteriore importante riduzione di sensibilità. Il virus integrato (cDNA dell'HIV) è presente nei leucociti. Il buffy-coat leucocitario ha un contenuto totale in DNA almeno 10 volte superiore a quello presente nella stessa quantità di sangue intero. Se si "spottano" $40 \mu \mathrm{l}$ di buffy-coat, pari a 3.46-7.73 $\mu \mathrm{g}$ di DNA, e si prelevano ed estraggono come da metodica quattro punches da $3.5 \mathrm{~mm}$ o due punches da $5 \mathrm{~mm}$ (DBCS), si ottiene una quantità di DNA genomico estratto di $2.40 / 5.37 \mu \mathrm{g}$ in un volume di $100 \mu \mathrm{l}$ di eluato. Se inoltre il DNA estratto dai punches viene eluito in $50 \mu \mathrm{l}$ di buffer invece di $100 \mu \mathrm{l}$, come da estrazione standard, la concentrazione raddoppia ottenendo una concentrazione finale di $4.8-10.74 \mu \mathrm{g} / \mu \mathrm{l}$ di DNA molto simile a quella ottenuta da $200 \mu \mathrm{l}$ di sangue intero (Tabella 1)

Tabella.I. Quantità di DNA $(\mu \mathrm{g})$ nelle tre differenti modalità di estrazione Quantità di DNA ottenuto da $200 \mu \mathrm{ldi}$

sangue intero ed eluito in $100 \mu \mathrm{l}$ 4-8

Quantità di DNA ottenuto da 2 punches da $5 \mathrm{~mm}$

di sangue intero (DBS) eluiti in $50 \mu \mathrm{l}$

Quantità di DNA ottenuto da 2 punches da $5 \mathrm{~mm}$

di buffy-coat (DBCS) eluiti in $50 \mu \mathrm{l}$ 


\section{MATERIALI E METODI}

Sono stati raccolti in tubi "vacutainer" contenenti $K_{2}$ EDTA 30 campioni di $5 \mathrm{ml}$ di sangue intero provenienti da pazienti HIV-1 positivi ricoverati presso il reparto malattie infettive dell’Ospedale Pediatrico Bambino Gesù di Roma e 20 campioni raccolti nella missione "Villaggio della Speranza “ Dodoma, Tanzania. Per ogni campione, $40 \mu \mathrm{l}$ sono stati spottati su "Micro Card FTA ELUTE” (Whatmann), $200 \mu \mathrm{l}$ sono stati estratti secondo la procedura manuale (QIAGEN "QIAamp DNA minikit") ed il rimanente è stato incubato a $37^{\circ} \mathrm{C}$ per 120 minuti. Il plasma separato è stato centrifugato a 1000 rcf per 10 minuti a temperatura ambiente. Il buffy-coat ottenuto è stato "spottato" sulle medesime
“Card” in ragione di $40 \mu \mathrm{l}$. I DBS e i DBCS (Dried BuffyCoat Spot) sono rimasti ad asciugare a temperatura ambiente per 24 ore. Due punches da $5 \mathrm{~mm}$ prelevati da ogni spot sono stati estratti con il kit DNA TISSUE (Biorobot EZ1 DSP “Qiagen”) ed eluiti in $50 \mu \mathrm{l}$ di buffer. Il "recovery" del DNA genomico è stato misurato amplificando il gene della ß-globina in Real-Time "sybr-green I" (Tabella 2). Gli estratti sono stati amplificati per il locus "pol" codificante la proteina integrasi del virus HIV-1 mediante nested-PCR e rilevazione in "Sybr-green I”(Tabella 2). Otto campioni HIV-Ab neg sono stati usati come controllo di specificità del test basato sul gene pol. (Tabella 3)

Tabella 2. Sequenze dei primers utilizzati nel corrente studio

Sequenze dei primers (5'-3') per la B-globina

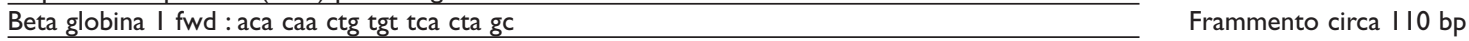
Beta globina 2 rev : caa ctt cat cca cgt tca cc

Sequenze dei primers (5'-3') per il gene pol codificante l'integrasi dell'HIV-I

pol fwd EST: agg att cRg gat Yag aag taa aYa tag $t$

pol rev EST: tgt cct gtt tct gct ggR ata acY tct gc

Frammento circa 349 bp

pol fwd INT: aat cag aRt tag tca Rtc aaa taa tag a

pol rev INT: cct tct aaa tgt gta caa tct aRt tgc ca

Tabella 3. controllo di specificità del test basato sul gene pol.

\begin{tabular}{ccccccc}
\hline ID n $^{\circ}$ & $\begin{array}{c}\text { Ctß-globina } \\
\text { Estrazione Standard }\end{array}$ & $\begin{array}{c}\text { Ctß-globina } \\
\text { Estrazione DBCS }\end{array}$ & $\begin{array}{c}\text { Ctß-globina } \\
\text { Estrazione DBS }\end{array}$ & $\begin{array}{c}\text { Ct PCR pol } \\
\text { Estrazione standard }\end{array}$ & $\begin{array}{c}\text { Ct PCR pol } \\
\text { DBCS }\end{array}$ & $\begin{array}{c}\text { Ct PCR pol } \\
\text { DBS }\end{array}$ \\
\hline 1 & 18.58 & 18.02 & 25.22 & $\geq 50$ & $\geq 50$ & $\geq 50$ \\
\hline 2 & 18.62 & 19.70 & 28.92 & $\geq 50$ & $\geq 50$ & $\geq 50$ \\
\hline 3 & 16.25 & 16.54 & 24.60 & $\geq 50$ & $\geq 50$ & $\geq 50$ \\
\hline 4 & 16.44 & 17.46 & 25.24 & 250 & $\geq 50$ & $\geq 50$ \\
\hline 5 & 18.08 & 19.49 & 25.95 & $\geq 50$ & $\geq 50$ & $\geq 50$ \\
\hline 6 & 20.52 & 20.72 & 27.78 & $\geq 50$ & $\geq 50$ & $\geq 50$ \\
\hline 7 & 18.63 & 21.28 & 25.80 & $\geq 50$ & $\geq 50$ & $\geq 50$ \\
\hline 8 & 17.12 & 21.12 & 24.80 & $\geq 50$ & 250 & $\geq 50$ \\
\hline
\end{tabular}

(Ct $=$ numero minimo di cicli in PCR Real-Time per osservare la positività del test)

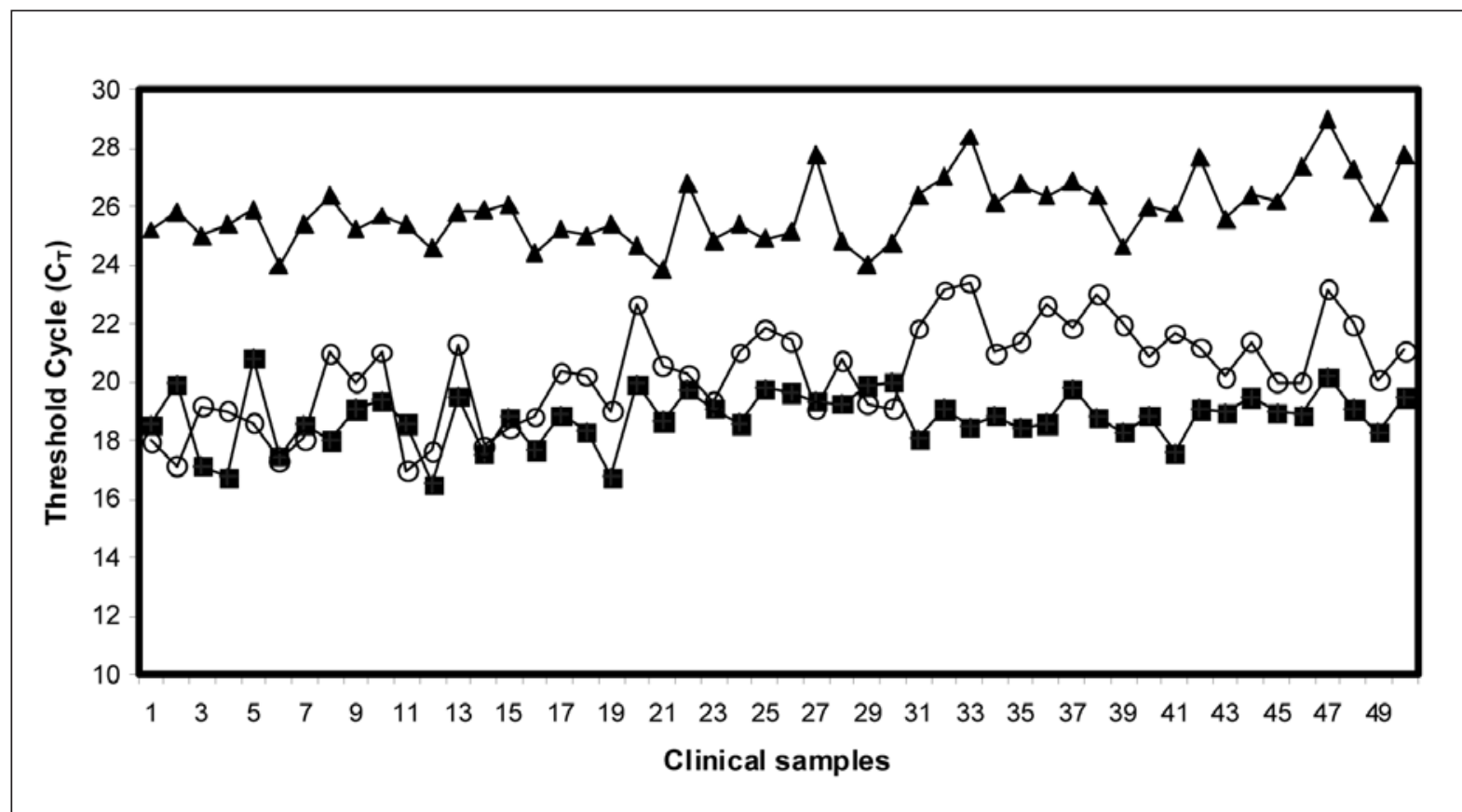

Figura I. Confronto fra le diverse quantità di B-globina ottenute utilizzando le tre tipologie di estrazione: sangue intero, DBS e DBCS (sono indicate come $C t$ ). $\mathbf{\square}, B$-globin $C t$ per sangue intero trattato con estrazione manuale (standard); $\mathbf{\Delta}, B$-globin $C t$ per DBS trattato con estrazione automatica; $\bigcirc$, B-globin Ct per DBCS trattato con estrazione automatica. 


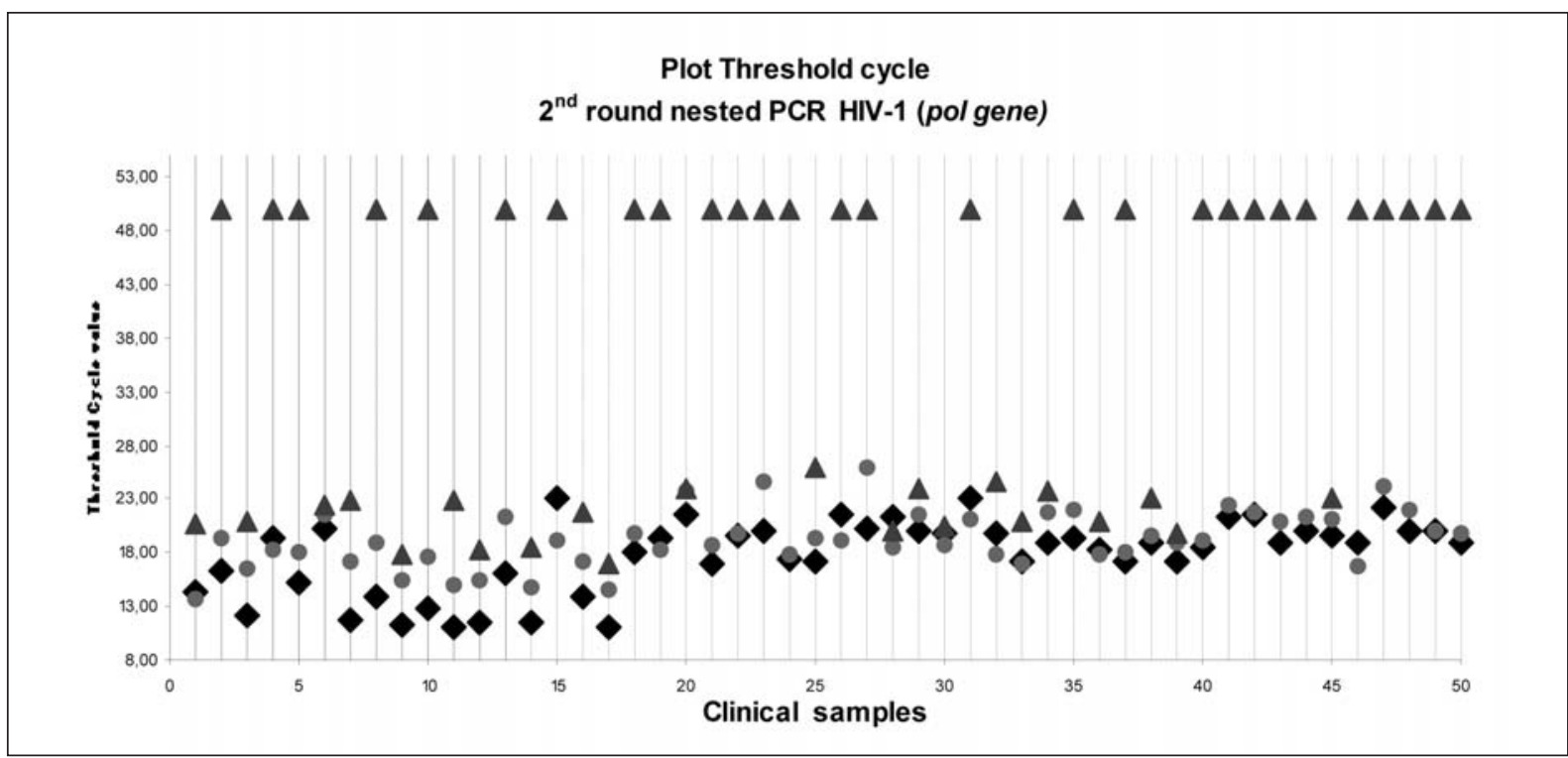

Figura II. Determinazione e confronto di diagnosi HIV-I mediante gene pol eseguita nelle tre differenti tipologie di estrazione: sangue intero, DBS e DBCS. $\diamond$, pol Ct per sangue intero trattato con estrazione manuale (standard); $\boldsymbol{\Delta}$, pol Ct per DBS trattato con estrazione automatica; $\bullet$, pol $C_{t}$ per DBCS trattato con estrazione automatica.

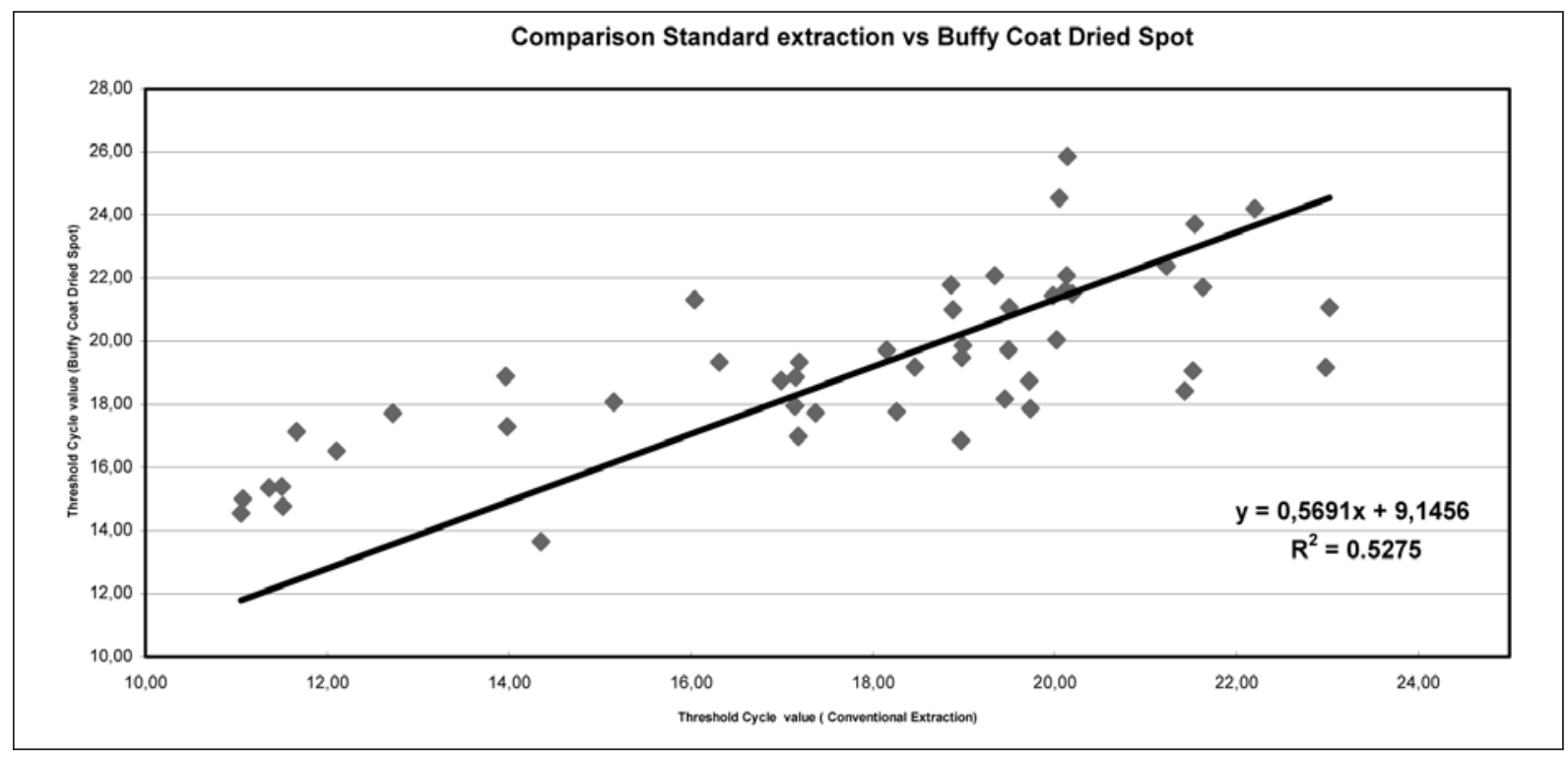

Figura III. Regressione lineare relativa ai Ct ottenuti al 2nd round della Nested-PCR, del gene pol del HIV-I: comparazione tra metodo standard (asse delle $X)$ e DBCS (asseY).

\section{DISCUSSIONE E CONCLUSIONI}

Il protocollo sperimentale adottato per la rilevazione del cDNA di HIV-1 a partire da spot di buffy-coat leucocitario è risultato un sistema dotato di un'elevata sensibilità. I risultati sperimentali confermano le considerazioni teoriche sull'efficienza di estrazione relative al "recovery" del gene della ß-globina; la quantità di DNA estratto dai DBCS è infatti molto simile a quanto è possibile ottenere a seguito di un'estrazione manuale. La quantità di DNA provirale integrato ricavato mediante rivelazione in Real-Time PCR ed espresso in cicli soglia (Ct), risulta sovrapponibile, sia che vengano estratti a partire da DBCS che in maniera convenzionale; mentre il test eseguito su DBS risulta essere significativamente meno sensibile. Le evidenze sperimentali dimostrano che la quantità di c-DNA recuperabile da DBS spesso non è sufficiente per la ricerca del c-DNA dell'HIV-1, nonostante l'utilizzo di tecniche d'amplificazione Nested-PCR. Il sistema di rivelazione in "Sybr Green I" è altrettanto specifico di quello tradizionale basato su gel di agarosio in quanto consente la verifica della corretta amplificazione del bersaglio mediante curva di dissociazione assicurando di fatto praticità, rapidità, e sensibilità del saggio.

\section{BIBLIOGRAFIA}

1. Alvarez-Munoz et al. 2005 High correlation of human immunodeficiency virus type- 1 viral load measured in dried-blood spot samples and in plasma under different storage conditions. Arch. Med. Res.36:382-386

2. Barbi et al. 2006. Diagnosis of congenital CMV infection via dried blood spots. Rev. Med. Virol. 16:385-392

3. Children and AIDS. Third Stocktaking Report.2008 Unicef publication

4. De Cock et al. 2000 Prevention of mother-to-child HIV transmission in resource poor countries: translating research into policy and practice. JAMA 283:1175-1182

5. Dunn et al.1995 The sensitivity of HIV-1 DNA polymerase chain reaction in the neonatal period and the relative contributions of intra-uterine and intrapartum transmission. AIDS9:F7-F11

6. EZ1 DNA Handbook, Qiagen, III edition 2009. 